\title{
Cloud ERP Systems: Anatomy of Adoption Factors \& Attitudes
}

\author{
Moutaz Haddara ${ }^{1}$, Asle Fagerstrøm ${ }^{2}$ and Bjørnar Mæland ${ }^{3}$ \\ 1,2,3 Department of Technology \\ Westerdals Oslo School of Arts, Communication and Technology, Oslo, Norway \\ ${ }^{1}$ Department of Computer Science, Electrical and Space Engineering \\ Luleå Tekniska Universitet, Luleå, Sweden.
}

Correspondence should be addressed to: Moutaz Haddara; hadmoa@westerdals.no

Received date: 12 January 2015; Accepted date: 14 May 2015; Published date: 17 September 2015

Academic Editor: Nicola Sfondrini

Copyright (C 2015. Moutaz Haddara, Asle Fagerstrøm and Bjørnar Mæland. Distributed under Creative Commons CC-BY 4.0

\begin{abstract}
Enterprise resource planning (ERP) systems have always been of interest to researchers across various research disciplines. Recently, the cloud computing paradigm has emerged to become one of most prominent technologies in business and academia alike. These new cloud accessibility and software delivery models have radically revolutionized the software market, especially ERP systems. However, while many vendors and software providers have adopted software-as-a-service (SaaS) models, few studies have explored the domain of cloud-based ERP systems - particularly information technology (IT) officers' attitudes toward these technologies. Based on our review of literature and the relevant theories, we created a questionnaire and sent it to IT executives in Norwegian companies. The questionnaire captured the respondents' perceptions of the benefits and disadvantages of cloud ERP. In general, the results confirm what has been reported in the literature. There were, however, some notable exceptions. One of the significant exceptions was the evident lack of data security concerns among the respondents, who ranked it as the least of their concerns. In addition, the promise of lowered total cost of ownership was not perceived as an appealing benefit, unlike what has been widely discussed in literature. Our findings show that respondents deemed vendor dependency and lock-in to be the paramount concerns of such cloud technologies, and system accessibility to be the significantly most advantageous. Finally, descriptive and inferential statistical analyses were conducted in this paper, and a regression analysis of the results was performed to identify the level at which the various benefits and advantages most affected our respondents' attitudes.
\end{abstract}

Keywords: Cloud, SaaS, ERP, adoption factors, attitudes.

\section{Introduction}

Enterprise resource planning (ERP) systems integrate data and processes inside organizations. Traditionally, data is centrally stored in a consolidated database.
This database serves as a central hub that records, shares, and disseminates data across the different business departments. ERP vendors promise their clients several benefits with their ERP systems. Besides the potential cost savings, one of the main

Cite this Article as: Moutaz Haddara, Asle Fagerstrøm and Bjørnar Mæland (2015), "Cloud ERP Systems: Anatomy of Adoption Factors \& Attitudes", Journal of Enterprise Resource Planning Studies,

Vol. 2015 (2015), Article ID 521212, DOI: 10.5171/2015.521212 
drivers for an ERP adoption is the technical and operational integration of the various business functions to synchronize the information stream with the material flow of goods and/or services (Haddara, 2014). ERP systems can aid in increasing competitiveness as they can provide timely reporting capabilities to management, including cost and operational information that is needed in making strategic decisions related to the enterprise's competitive position (Beheshti, 2006). In addition, acquisitions, mergers, and joint ventures are also usually drivers for organizations to adopt ERP systems, in order to unify, exploit, and administer the massive information and work flow among them.

Due to their scale and their need for substantial dedicated resources, ERP systems have been a focus for both researchers and practitioners. Moreover, they require many organizational changes, which could inflict high risks of failure if the implementations are not thoroughly planned, executed, and managed. Statistics from literature and practice show high rates of implementation failures (Elragal \& Haddara, 2013). Given the complexity and high resource consumption of ERP systems, enterprises adopting them need to think about many things, and adoption cost is at the top of the list (Elragal \& Haddara, 2010). Through the last decades, many technologies and infrastructural changes have been introduced to ERP systems, like web enablement, service-oriented architecture (SOA), and cloud computing. The cloud computing and SaaS domains have become two of most prominent and stimulating computing technologies in business and industry. Originally, cloud computing was built on the foundation of several technologies, such as grid computing, which includes clustering, server virtualization, and dynamic provisioning, as well as SOA shared services and large-scale management (Zhao, Sakr, Liu, \& Bouguettaya, 2014). The emergence of cloud computing has enabled many enterprises with handy and ondemand network access to share a bundle of resources. These resources can include networks, servers, data storage devices, applications (e.g., ERP), and so on. This bundle of resources can be provided and deployed with minimal management effort from the customer side. Cloud computing promises of, e.g., resource efficiency, lower entry barriers, scalability, and mobile compatibility have enticed companies of all shapes and sizes to explore how it may benefit their businesses (Ghaffari, Delgosha, \& Abdolvand, 2014). Adoption of this technology can come in many forms. Cloud computing is a broad concept, as reflected by its multilayered architecture and concurrent service models. While the options are plenteous, the seemingly most common way for an organization to incorporate cloud computing is by leasing web-based software applications, also known as the software-as-a-service (SaaS) model. A diverse range of software applications is available through the SaaS model. Within this dominion, we can find everything from simple applications like office suites, web conferencing software, and e-mail applications to more strategic and complex software such as customer relationship management (CRM), supply chain management (SCM), and ERP systems. The last, ERP systems, is the main focus of this research. Like cloud computing, ERP is a vastly researched topic within the domain of information systems (IS) and has had a remarkable impact on the way businesses are organized. Despite the plethora of research conducted on both phenomena separately, there is a somewhat surprising shortage of literature that assesses cloud/SaaS-based ERP systems (Elragal \& Haddara, 2012).

This apparent shortage of existing literature does not imply that the topic is irrelevant. There are an increasing number of cloud ERP implementations among businesses, especially small and mediumsized enterprises (SMEs) (Salim, 2013). In 2012, the Gartner Group predicted that by 2016, cloud-based ERP systems would have more than doubled their revenue shares since 2011 (from 8 to $17 \%$ ). Cloud ERP (along with subscription-based and hosted ERP) saw a $410 \%$ growth rate in the period of 2005-2006, with revenues climbing from $\$ 76$ million to $\$ 387$ million (Jacobson, Shepherd, D'Aquila, \& Carter, 2007). In a more recent study, the Gartner 
Group surveyed organizations' cloud ERP adoption strategies; a total of $47 \%$ of the respondents claimed that they intended to transfer their core ERP systems to the cloud within 5 years $-26 \%$ of these within the next 3 years (Columbus, 2014). The renowned research group additionally stated earlier this year that the onpremises ERP systems of today are likely to be referred to as "legacy systems" by 2016 (Kanaracus, 2014).

Overall, cloud-based applications are seeing strong and systematic growth and are likely to be a force to be reckoned with in the years to come, especially in the ERP arena (Elragal \& Haddara, 2012). This justifies an assessment of organizations' beliefs and attitudes in regard to them. As part of the cloud-computing paradigm, such systems have certain embedded features that differentiate them from their on-premises counterparts - some of which may be more desirable than others. The goal of this study is thus to explore what traits and features of such systems are regarded as most (and least) desirable by organizations. This insight will be gained through surveying senior IT employees in a sample of Norwegian enterprises.

The following research question serves as the main grounds for this research:

What benefits and disadvantages of cloudbased ERP systems shape Norwegian organizations' attitudes toward and perceptions of them?

This paper is organized as follows: Section 2 presents relevant literature. The theoretical framework and research hypotheses are provided in section 3. Section 4 introduces the research method applied. Section 5 provides an overview of the findings, followed by a discussion of the results in section 6. Finally, conclusions and future research avenues are discussed in section 7 .

\section{Related Literature}

\section{ERP systems}

ERP systems are large modular software packages that allow integrated transaction processing and access to relevant information for multiple organizational units and multiple business functions. These business functions include financials and accounting, human resources, supply chain, and customer services. The standard in-house ERP system is traditionally based on a central large database. This database gathers data from the various business functions. The database also feeds the data into modular applications supporting virtually all of the company's business activities - across functions, across business units. When new data is entered at one corner of the organization, related data in other units is then automatically updated accordingly. Most companies expect ERP to reduce their operating costs, increase process efficiency, improve customer responsiveness, and provide integrated decision information (Haddara, 2012). They also want to standardize processes and learn the best practices embedded in ERP systems to ensure quality and predictability in their global business interests by reducing cycle times from order to delivery (Elragal \& Haddara, 2012). According to Deltour (2012), ERP adoption projects differ in their scope and progress among organizations. The ERP project scope includes time duration, estimated and available budgets, and the number of implemented modules. On the other hand, the adopted project approach includes specifications definition, implementation methodology, and terms of external parties.

ERP implementations pose several challenges for adopting organizations. Some of these challenges are related to the substantial time and cost escalations, technical problems, and the degree of business process re-engineering (BPR) needed to accommodate the new system. While the average ERP budget has decreased, according to a recent survey conducted by Panorama Consulting Group (Solutions, 2014), $54 \%$ of 192 enterprises 
surveyed still surpassed their estimated budgets in 2013. Also, $72 \%$ surpassed their estimated project schedules, with an increase of $11 \%$ over 2012 , as depicted in Table 1.

Table1: 2014 ERP Report (Adapted from Panorama Consulting Solutions, 2014).

\begin{tabular}{|l|c|c|c|c|c|}
\hline Year & Cost & $\begin{array}{c}\text { Percentage } \\
\text { of cost } \\
\text { overruns }\end{array}$ & Duration & $\begin{array}{c}\text { Percentage of } \\
\text { duration } \\
\text { overruns }\end{array}$ & $\begin{array}{c}\text { Percentage } \\
\text { receivind 50 \% } \\
\text { or less benefits }\end{array}$ \\
\hline $\mathbf{2 0 1 3}$ & $\$ 2.8 \mathrm{MM}$ & $54 \%$ & 16.3 months & $72 \%$ & $66 \%$ \\
\hline $\mathbf{2 0 1 2}$ & $\$ 7.1 \mathrm{MM}$ & $53 \%$ & 17.8 months & $61 \%$ & $60 \%$ \\
\hline $\mathbf{2 0 1 1}$ & $\$ 10.5 \mathrm{MM}$ & $56 \%$ & 16 months & $54 \%$ & $48 \%$ \\
\hline $\mathbf{2 0 1 0}$ & $\$ 5.5 \mathrm{MM}$ & $74 \%$ & 14.3 months & $61 \%$ & $48 \%$ \\
\hline
\end{tabular}

In addition, customization and change management are also considered critical challenges during the project. No matter the size of the enterprise, all ERP implementations require careful project management activities, committed top management, and a dedicated team (Hustad \& Olsen, 2014). Post implementation, enterprises usually experience a "shakedown" phase, during which they face challenges at the same time as they have to adapt to the newly reengineered processes (Elragal \& Haddara, 2012). This might result in decreased productivity or operational disruptions for a period of time.

\section{ERP systems in Norway}

Scandinavian organizational culture and management practices tend to be based on collaboration and consensus (Grenness, 2003). Norway is considered a technologically contemporary society with sophisticated telecommunications and a high Internet penetration rate: $97.2 \%$ of the population (CIA, 2014). Despite the significant Internet penetration and usage, it is reported that data and Internet security are generally not a large concern of the Norwegian population (NorSIS, 2010). Privacy concerns have, however, seen somewhat of an increase in later years (Datatilsynet, 2014). As for the ERP market in Norway, the reports "Business Systems, 2013" by Herbert Nathan \& Co (2013) and
“ERP Study, 2011" (Christensen, 2011) give a thorough overview of the Norwegian ERP conditions. According to the survey conducted by Herbert Nathan \& Co (2013), SAP has the highest market share in Norway (based on license value), with Visma a close second and Microsoft in a solid third place. These vendors aggressively compete for the SME market. Norwegian businesses usually retire and replace their ERP systems every 8-10 years. Also, the survey results suggest that the most common motivations for companies to replace their existing systems are related to replacing outdated technology (61\%), streamlining business processes $(60 \%)$, or improving data quality (59\%). In addition, close to $40 \%$ of ERP-adopting organizations managed to implement their systems within the scheduled time, while $58 \%$ surpassed their estimated schedules. Additionally, $36 \%$ of businesses implementing a medium-sized ERP system experienced fewer benefits than initially expected. Moreover, in contrast to the literature, the survey claims that customer satisfaction with ERP systems varies according to the system's size. For example, medium-sized systems are generally held in the highest regard, with $57 \%$ of customers expressing a high or very high level of satisfaction; $27 \%$ of adopters of small systems had a low or very low degree of satisfaction, and $21 \%$ of companies adopting large-scale systems expressed similar discontent. Finally, the 
report suggests that SaaS- and cloud-based ERP systems have seen rapid acceptance among Norwegian enterprises. On the other hand, the survey conducted by Hjort Christensen (2011) shows that the overall percentage of respondents who expressed high/very high satisfaction with their systems is around $75 \%$. However, a notable degree of these respondents expressed a need for more functionality in their ERP systems than what they were currently using.

\section{Cloud/SaaS ERP}

In accordance with the different cloud computing delivery and service models, cloud-based ERP may take several forms. An ERP system may, for instance, be deployed as hosted software, where the license is purchased but all hosting, hardware, upgrades and general maintenance are handled by either the ERP provider or an external third party (Arnesen, 2013). A new license is not necessarily required, as organizations also may migrate their existing ERP system onto a private cloud. The most common type of cloud-based ERP systems, however, are based around the SaaS delivery model and are occasionally referred to as EaaS (ERP-as-a-service) (Juell-Skielse\&Enquist, 2012). These are the primary focus of this research. One study surveyed 297 German companies in order to uncover both their degree of SaaS adoption and their attitude toward adopting enterprise-oriented application types like CRM, BI, content management, ERP, and so on (Benlian, Hess, \&Buxmann, 2009). The study revealed that SaaS-based ERP systems are only hesitantly adopted at present. The authors link this to the high degree of strategic significance and adoption risks of ERP systems. These tendencies, however, maybe are shifting. The Aberdeen Group has monitored organizations' willingness to consider SaaS-based ERP solutions since 2006.Their assessments imply, for instance, that cloud-based ERP systems are being adopted by small organizations at a rapid pace; in 2012, $26 \%$ of respondents within the small organizational category had deployed cloud ERP - a significant leap from $17 \%$ in 2011 (Castellina, 2012). Their work indicates that companies' willingness to adopt cloud ERP doubled in the period 2006-2013 (Castellina, 2013) and that SaaS-related concerns are generally decreasing (Castellina, 2011).

\section{Total cost of ownership (TCO)}

Traditional in-house ERP system implementations require a substantial budget upfront and are resource consuming. In addition, costs frequently escalate during these implementation projects (Haddara \& Elragal, 2013). The expected future cost savings after successful implementations are often highlighted by academics as the primary driver for adoption and investment justification in ERP literature (Salleh, Teoh, Chan, Pan, \& Cao, 2012). On the other hand, up-front costs and investments are considerably low in cloud ERP. Numerous surveys on cloud ERP serve as evidence for this; in Gill's survey (2011), ranked as number 1 , with $30 \%$ of the respondents listing it as the most beneficial trait of cloud ERP. It tops the "Positive Factors Influencing SaaS Decisions" in Aberdeen Group's study, with $75 \%$ of respondents listing it (Castellina, 2011). A study of 600 Czech organizations found it to be the strongest motivational factor for cloud adoption (Feuerlicht, Burkon, \&Sebesta, 2011). A final example is Benlian and Hess's survey of 349 German IT executives, where "cost advantages" was perceived as "the strongest and most consistent opportunity factor" in regard to cloud adoption (Benlian \& Hess, 2011).

\section{Lower maintenance/hardware costs and less demand for internal competence}

Supporting the ERP system may require significant embedded costs, such as hardware requirements and ongoing maintenance and upgrade expenses. In cloud-based ERP system environments, upgrades are handled by the hosting service provider. The service provider also serves all clients at once due to the multi tenancy architecture and common code (Xin\&Levina, 2008). 
From a cost-oriented perspective, this "outsourcing" may be highly beneficial as the costs associated with maintenance and hardware, are quite high. Both SAP and Oracle have at some point had annual maintenance fees that surpassed $20 \%$ of their software purchase price (Armbrust, Fox, Griffith, Joseph, Katz, Konwinski, Lee, Patterson, Rabkin, et al., 2010). Arnesen (2013) states that the annual cost for maintaining and supporting an onpremises ERP system is usually around 18$25 \%$ of the license cost, which excludes the factor of in-house personnel. IT maintenance takes its toll on budgets; it is reported to count for around two-thirds of the average IT budget of American companies (Marston et al., 2011). "Ease of upgrades" ranked fourth on Gill's survey, with $9 \%$ (Gill, 2011). Maintenance-related savings are not limited to the hardware aspect alone. Maintaining the technology also requires that companies acquire or train specialized staff to sustain the onpremises solution (Zhang, Cheng, \& Boutaba, 2010). This might be a money drainer; it has been reported that in the United States, $60 \%$ of the average IT staffing budget is spent on support and maintenance (Carr, 2005). When the computing resources are hosted externally, the requirements for both staff education and employee "headcount" are diminished (Linthicum, 2009). IT staff may then focus less on operational duties and more on value creation and profitability for the company.

\section{Faster implementation and lower up- front investment}

As explained in section 2.1, the acquisition and implementation of an ERP system is no easy task. In an enterprise context, these systems are among the most expensive, most time-consuming, and overall riskiest IT investments there are (Deltour, 2012). With cloud ERP, the system is configured in accordance with information and parameters provided by the new client before a new system version is created for them (Torbacki, 2008). Thus, the implementation process tends to be considerably shorter and cheaper; cloud ERP adopters report fewer months until
ROI (23.61 compared to 31.09 for onpremises) and fewer months until "going live" (6.95 compared to 11.02 for onpremises) (Castellina, 2011).

The simplified and less demanding (in terms of both time and money) implementation, is highlighted as a strong benefit in several literary sources (Salleh, Teoh, \& Chan, 2012). In an SME-dominated (and relatively small-scale) survey of organizations within the Czech Republic, rapid implementation ranked as the second strongest motivator for cloud adoption, surpassed only by improved scalability (Feuerlicht et al., 2011). "Lower up-front costs" ranked second also in Aberdeen Group's 2012 survey of what positive factors most affect cloud adoption decisions (Castellina, 2011). The support is not unanimous, however; "Speed of deployment" ranked last, with $5 \%$, in the survey conducted by Gill (2011). Many organizations within the SME domain find the initial investments required for onpremises ERP too high to justify adoption. Owing to the lower investment in terms of both time and money, SMEs are turning to cloud ERP at an increasing rate, and vendors are fiercely competing for this segment (Co, 2013; Lewandowski, Salako, \& Garcia-Perez, 2013).This lower need for initial investment is closely correlated with the TCO element, as the implementation period and its embedded expenses are taken into account when measuring TCO. Some authors view the shortened implementation period of cloud and SaaS adoption not as cost reduction in itself. Rather, they perceive it to be a rearrangement of the expenses, as the initial capital investment of acquisition is replaced by operational costs (Hofmann \& Woods, 2010). The extent of these operational expenses may vary, as noted in the TCO assessment.

\section{Strategic flexibility / scalability}

If we take a moment to recall the NIST definition of cloud computing, we know that two of its central characteristics are (on-demand) self-service and rapid elasticity (Mell \& Grance, 2011).Due to the elasticity of outsourced cloud services, 
clients may adjust their capacity (and thus expenses) in accordance with their needs, ensuring a more cost-efficient resource management (Lewandowski et al., 2013). For instance, say a company experiences strong growth and needs to expand its number of employees/system users. With a cloud infrastructure, these users could immediately and with great ease be added to the system with minimal or no need for intraorganizational expansion of IT resources to support this additional load; the expenses would reflect only the increased usage of the system (Iyer\& Henderson, 2010; Marston et al., 2011). Resources may, naturally, also be deallocated in the same manner. The ability to alter resource consumption at such a rapid pace can be highly beneficial for businesses; examples from the literature include increased capacity for businesses

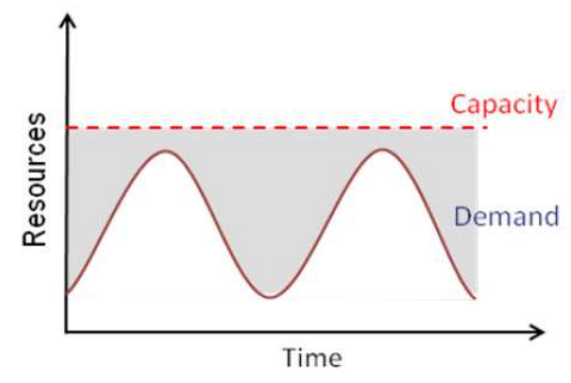

Static service operating in a season-sensitive (like Christmas and other holidays) domain (Arnesen, 2013), as well as downscaling during employee holidays. This ability to scale computing capabilities on demand is a distinct trait of cloud computing and is rather consistently highlighted as a significant benefit. In Benlian and Hess's (2011) survey of 349 IT executives, "strategic flexibility" was the second most valued benefit. It also ranked second in the survey conducted by Koehler, Anandasivam, and Dan (2010). Armbrust et al., state, "This elasticity of resources, without paying a premium for large scale, is unprecedented in the history of IT" (Armbrust, Fox, Griffith, Joseph, Katz, Konwinski, Lee, Patterson, \& Rabkin, 2010). A highly illustrative figure can be found in the work of Iyer and Henderson (2010), as presented below.

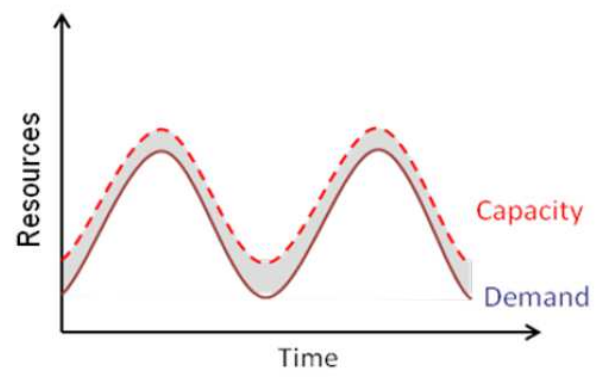

Service in the cloud

Figure 1: Cloud computing removes the need for peak loadcapacity (Iyer\& Henderson,

\section{Accessibility and collaboration}

In the literature, a frequently suggested key benefit of cloud applications is the high level of location-independent accessibility. In most cases, the user needs only a web browser and an Internet connection to access the application. In the current global business environment, this is a significant advantage. Enterprises are eager to lower their response time and have around-theclock access to real-time data in order to maintain competitiveness (Castellina, 2013). The literature indicates that accessibility is perceived to be one of the top benefits of cloud ERP systems. In Gill's survey, it was a close second, at $28 \%$, following TCO's $30 \%$ (Gill, 2011). Among SMEs in Singapore, "flexibility to access
2010).

application" was the clear predominant reason to consider cloud ERP systems (Koehler et al., 2010).

\section{Security and data ownership}

Regarded as a substantial barrier, securityrelated issues are, according to several studies, the main concern and inhibitor of adoption of cloud ERP and SaaS applications in general. In 2010, the 1105 Government Information Group and Beacon Technology Partners conducted a survey of federal IT managers to determine their attitudes toward cloud computing. The results indicate that the paramount cloud computing concern is security. Security issues include potential data loss or leakage, robust identity authentication 
and credential management, and secure and timely identity provisioning. Other concerns include effective data encryption, physical security, insecure application programming interfaces, and account, service, and traffic. In Gill's survey, a distinct majority found it to be the most negative element of cloud ERP (Gill, 2011). Similarly, the Aberdeen Group discovered that of all respondents unwilling to consider a cloud-based ERP solution, $66 \%$ felt that way because of security concerns almost twice as many as the next-ranked reason (38 \%) (Castellina, 2012). In Benlian and Hess's (2011) study, both adopters and non adopters of cloud solutions perceived security issues to be the biggest risk. Cloud computing in general is subject to similar tendencies. In an ongoing annual IDC survey, the respondent CIOs continuously list security as the top challenge of cloud computing (Feuerlicht et al., 2011). Another survey (Shimba, 2010) also found security issues to be the main perceived barrier to cloud adoption, while simultaneously discovering that a vendor's security practices are the main indicator of trustworthiness.

\section{Theoretical Framework}

The initial phase of this study was to discover whether any of the established IS theories could serve as theoretical lenses for this study. The theories could guide us to identify the topics and dimensions to tackle in our survey. Also, they could aid us in understanding and interpreting the findings. Initially, several theories were investigated; however, we identified two theories as strong candidates for adoption in this research. The first was Rogers's Diffusion of Innovations (2010) and Davis's Technology Acceptance Model (TAM) (1985). When we conducted a detailed relevancy check of TAM, we found it to be rather irrelevant to our research in its core focus. As this research is preoccupied primarily with cognitive processes prior to the actual system adoption/acquisition (attitudes, risk assessment, weighing benefits against disadvantages, etc.), we thought that TAM might be unfit as its primary focus is acceptance, as opposed to adoption/acquisition. It can be said that TAM focuses on a later stage, namely after the acquisition has already taken place and is to be assimilated (accepted) into an organization or an individual's usage patterns. We also found that our concerns were echoed by $\mathrm{Wu}$ (2011). The work of Benlian et al., (2009) assessed the topic of cloud adoption by applying the Theory of Reasoned Action (TRA). TRA (Figure 2) was initially presented by Ajzen and Fishbein (1980) and was a predecessor to TAM (Davis, 1985). Put briefly, TRA consists of two dimensions that impact the intention to perform a specific behavior: the attitude toward act or behavior and the subjective norm. As attitudes and perceptions are of paramount importance to this research, we initially found TRA to be promising. 


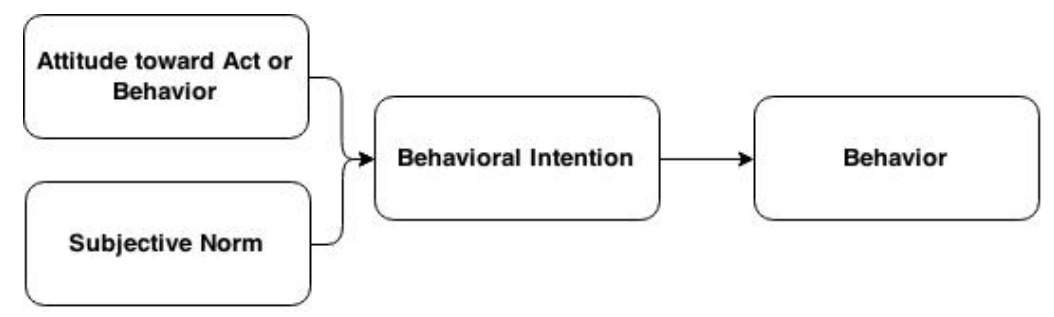

Figure 2: The Theory of Reasoned Action (adapted from Ajzen \& Fishbein, 1980).

On the other hand, a key limitation of TRA is its exclusion of factors of behavioral control and its embedded limitations (Chang, 1998). The absence of such contextual modifiers essentially implies that when an individual/entity has formed an intention to conduct a certain act or behavior, he/she/it will be free to perform this act or behavior without restraint. In short, it excludes relevant factors such as time and resources (monetary or otherwise). Ajzen (1991) acknowledged this limitation in the Theory of Planned Behavior (TPB), presented in Figure 3, which adds the perceived behavioral control (PBC) dimension to the TRA model, taking the above into account. While TRA has gathered significant empirical support since its inception, there is also considerable empirical evidence that implies that the addition of PBC tends to improve the "predictability of intention" (O’Keefe, 2002).

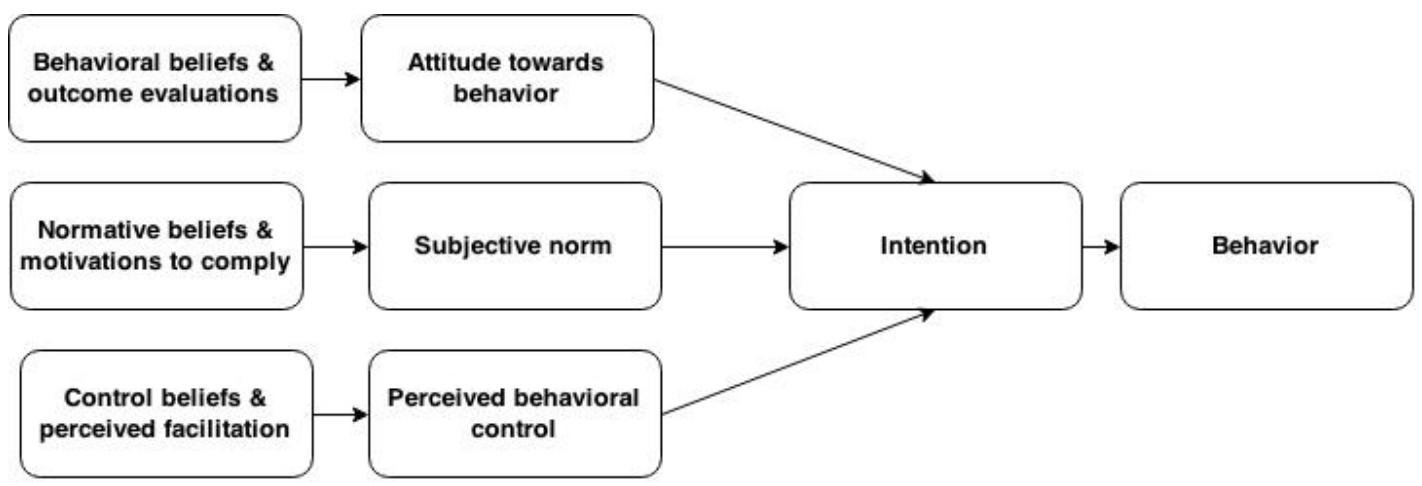

Figure 3: The Theory of Planned Behavior (adapted from Mathieson, 1991)

\section{Components of the Theory of Planned Behavior}

\section{Attitude toward behavior (ATT)}

In a nutshell, the attitude toward a given behavior is derived from the strength of the belief that the behavior will produce a given outcome, as well as the evaluation of these outcomes on a positive/negative scale (Francis et al., 2004). By measuring salient beliefs, researchers can assess what underlying cognitive evaluations form the attitude toward a given behavior (Ajzen, 2002). The ATT construct has generally been considered to have a strong relationship with actual behavior (O'Keefe, 2002) and thus serves as a strong predictor for behavioral intention. The salient beliefs in this case are the perceived benefits and disadvantages of cloud/SaaS ERP systems.

\section{Subjective norm (SN)}

The subjective norm is found in both TRA and TPB. Montano and Kasprzyk (2008) explain that SN is defined by a person's "normative beliefs that is, whether important referent individuals approve or disapprove of performing the behavior, 
weighted by his or her motivation to comply with those referents."Consequently, it is theorized that the expectations and opinions of important people have a significant impact on the actual shaping of a behavioral intention. Intention in favor of a given action/behavior translates into a positive SN, while intention against means that there is a negative SN. SN, like the other constructs, is perceived and, according to Montano and Kasprzyk, is related to the phenomenon of "social pressure." The significance SN has for behavior intention tends to vary significantly, but it is consistently found to be a factor (Chau\& Hu, 2001).

\section{Perceived behavioral control (PBC)}

The PBC dimension is a cognitive assessment of the degree to which the act or behavior actually can be performed with the assets, resources, and opportunities (e.g., time and money) available within the context in question (Ajzen, 1985). These beliefs can be based on prior experience with the behavior in question but are likely to be influenced by secondhand information (Harrison, MykytynJr, \& Riemenschneider, 1997). PBC has been proven to be a considerably stronger predictor on the actual behavior intention when the degree of control is perceived to be low as opposed to when there is a perceived high level of control (Madden, Ellen, \&Ajzen, 1992).

\section{Research hypotheses}

Based on the literature and theories presented above, the following hypotheses are proposed. See Figure 4.

H1a: Lower TCO is perceived as the most significant benefit.

H1b: TCO is a significant predictor of attitude.

H2a: Security concerns are perceived as the most significant disadvantage.

H2b: Security concerns are the most significant predictor of attitude.

H3a: Accessibility is perceived as a significant benefit.

H3b: Accessibility is a significant predictor of attitude.

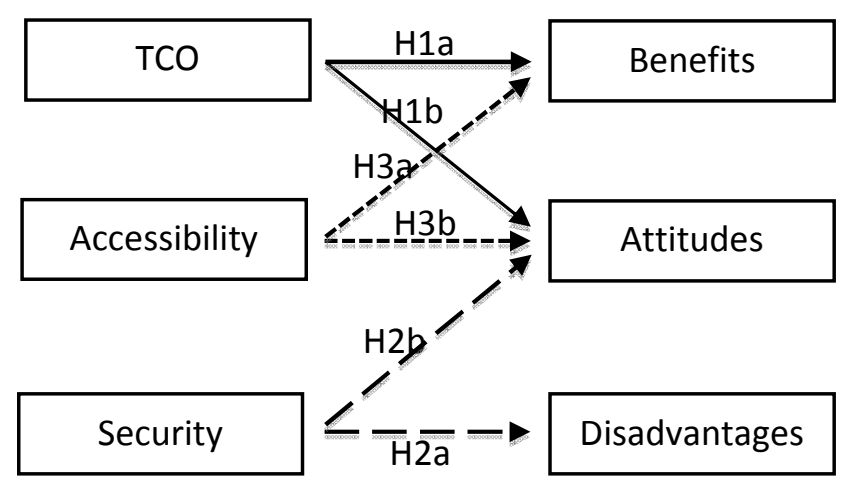

Figure 4: Research hypotheses.

\section{Method}

As previously mentioned, the primary aim of this research is to assess the attitudes and perceptions of Norwegian companies in regard to cloud- and SaaS-based ERP systems, with a strong emphasis on benefits and disadvantages. It thus seemed reasonable to choose the survey as a data collection method and to craft a questionnaire to be sent to a sample of the population. The findings are represented by descriptive and inferential statistics. Questionnaire development

We used the Internet-based survey development tool SurveyMonkey (www.surveymonkey.com). Respondents with no previous experience with ERP installations and no intentions for future 
adoptions were kindly asked not to complete the survey, as they were outside our target population. The reason for this was to avoid skewed results due to a lack of interest in the subject matter. Overall, the questionnaire design and the wording of the statements were strongly influenced by TPB guidelines (Ajzen, 1991, 2002; Francis et al., 2004), as well as the surveys of Chauand $\mathrm{Hu}$ (2001).

\section{Measures}

The TPB model served as the base construct for assessing our respondents, namely the beliefs that form attitude, subjective norm, perceived behavior control, and intention. Demographic data was also acquired, including company size, career length, company's industry, current ERP installation type, and so on. Respondents currently using ERP systems were asked to evaluate these in terms of satisfaction, mission criticality, and whether they were outdated. Furthermore, respondents were also asked to rate their own perceived knowledge of ERP and cloud computing technology. A primary focus was on the salient beliefs (benefits and disadvantages) that form attitude, as this was to be the main subject of analysis. Using a 10-point Likert scale, respondents were asked to state their level of agreement $(1=$ strongly disagree, $10=$ strongly agree) or perceived probability (1 = Low perceived probability, $10=$ High perceived probability) with statements that represented beliefs. Probability was used for SN- and PBC-related statements.

\section{Pilot study}

A pilot study was held to test the questionnaire reliability and relevance. Several measures were used to gather respondents for the pilot study. A request was posted on two relevant Norwegian groups on LinkedIn, namely "Forretningssystemer Norge" (Business Systems Norway) and "DND Den Norske Dataforeningen" (The Norwegian Computer Society). The posts briefly explained the goals of the study, as well as the reason for posting (gathering feedback). Respondents evaluated the survey as "Very Good,"“Good," or "OK." One respondent commented, "I think that you properly assess important matters, so the questionnaire appears as relevant."There were, however, some recurring comments that illuminated room for potential improvement. One example was the respondents' reaction to the inclusion of an "unpleasant-pleasant" measurement scale. According to the literature, the evaluation that makes up attitude tends to have two subcomponents, the first being an assessment of the risk benefit of the behavior, the other more experientially oriented and dealing with the (un)pleasantness of performing the behavior. While the literature recommends the inclusion of both subcomponents in the questionnaire (Ajzen, 2002; Francis et al., 2004), we had doubts as to whether it would be natural in this particular questionnaire. When the reviewers also deemed it to be somewhat misplaced, it was removed from the questionnaire. Another valuable observation made by multiple respondents was the lack of specificity in regard to cloud computing. One respondent aptly commented: "The definition of cloud is vague. I interpret the intention of this study to primarily cover SaaS-based systems from third-party providers, but I am in doubt whether it also is meant to cover systems (open source or licensed) operated internally on a virtualized platform (PaaS)." As a result of these remarks, later iterations of the questionnaire explicitly stated that its focus was on cloud-based ERP systems within the SaaS realm. The pilot testers more or less unanimously found the benefits and risks in the survey to be highly relevant and representative of reality. Some respondents found the questions to be somewhat similar at times. While the overall semantics and wording were approved by the respondents, some implied that the amount of text - and general content - could benefit from being somewhat shortened. Measures were thus taken to improve this in the final questionnaire. 


\section{Gathering respondents}

The survey targeted senior IT staff, including CIOs, CTOs, and IT directors, in Norwegian enterprises. According to Statistics Norway (SSB), there were 526,703 businesses in Norway at the beginning of 2014, of which $82.3 \%$ had 04 employees (Sentralbyrå, 2014).Companies within this range were regarded as being too small to be concerned with ERP systems. The remaining $17.7 \%$ were regarded as an eligible population for assessment. But seeing how the population totaled 93,194, it was apparent that a significant degree of sampling had to be done. Two different sampling techniques were applied: one nonprobabilistic, convenient (Oates, 2005), and the other one probabilistic, combining the systematic and stratified approaches (Oates, 2005). The overarching goal of both was to ensure that the sample consisted of relevant respondents. In the case of the nonprobabilistic technique, the Wikipedia entry for "Norwegian companies" was used to get an overview of companies. For the probabilistic technique, the company database/search engine www.purehelp.no was used for respondent acquisition. Each address along with company name (and, if a direct contact, title) were then saved in an Excel worksheet.

\section{Sample size and contact}

The process described above resulted in a list of 886 companies. Of these, 25 either were listed twice or had (according to their website) their corporate headquarters outside of Norway. Another 22 had erroneous mail addresses listed, resulting in delivery failure upon sending the questionnaire. The total size of the population sample was thus $839 ; 767$ of these were contacted via e-mail, while the remaining 72 were approached through contact forms on their company website. A week after the initial mail was sent, reminder e-mails were sent to respondents listed with an e-mail address. This excluded those who had (1) responded to the initial contact, (2) explicitly confirmed that they had answered the questionnaire or forwarded it internally, (3) provided contact information at the end of the questionnaire, or (4) explicitly confirmed that they would not complete the survey. In total, 485 reminder e-mails were sent.

\section{Response rate}

The first outreach resulted in 177 survey participants. After the reminder e-mail was sent, an additional 60 respondents (an increase of $33.89 \%)$ answered the questionnaire. The total number of unfiltered respondents was thus 237, giving a response rate of $28.24 \%$. Five days after the reminder e-mail was sent, the respondent data was exported from SurveyMonkey. The export excluded participants that had not completed the questionnaire in its entirety, so the findings are based on the answers of 180 respondents $-20.31 \%$ of the total sample.

\section{Findings}

\section{General demographics}

Specific industries were significantly better represented than others within our sample. The largest segments were industry and production, construction, and other; see Figure 5. Respondents placing themselves in the "Other" segment were asked to specify which industry they belonged to. The segment consisted of a wide variety of different industries, where the most frequent answers were "Oil and Gas", "Real Estate," and "Research \& Development." The sample had a relatively balanced distribution of small, medium, and large companies. 


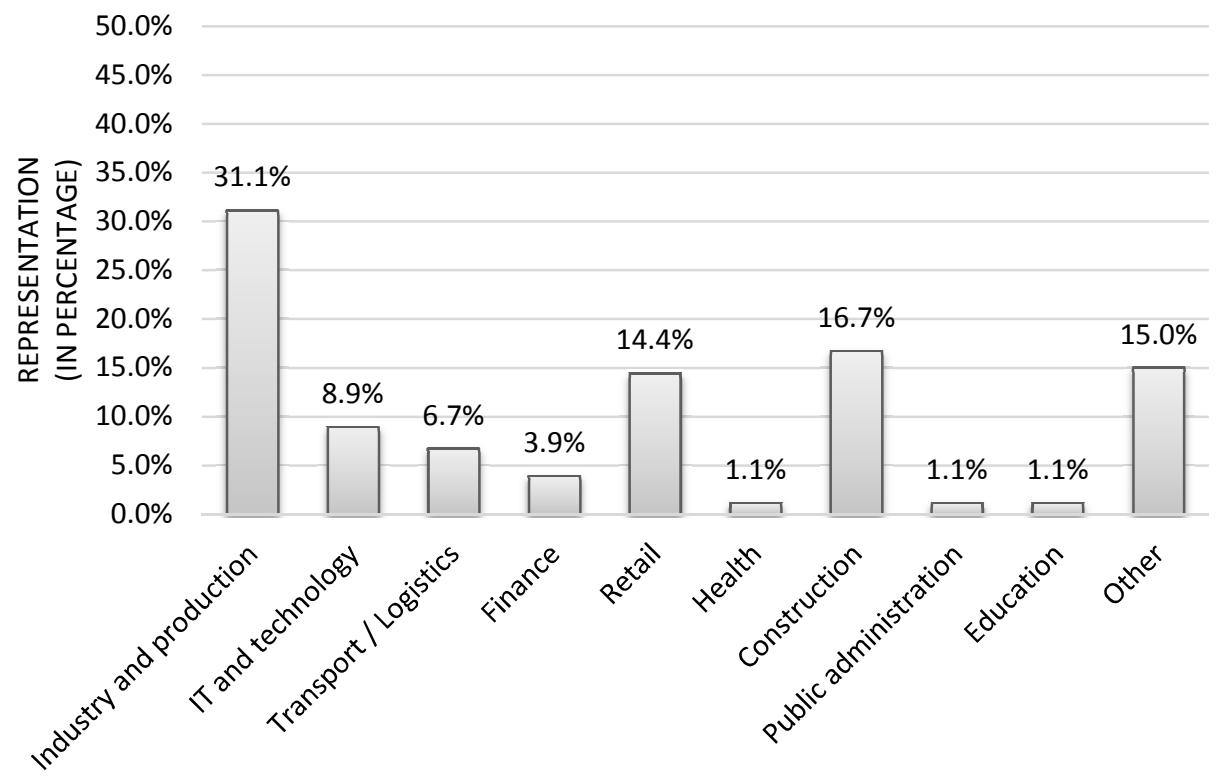

INDUSTRY

Figure 5: Respondent companies by industry

As presented in the following figure, the predominant size ranges were 101-500 employees and 21-50 employees.

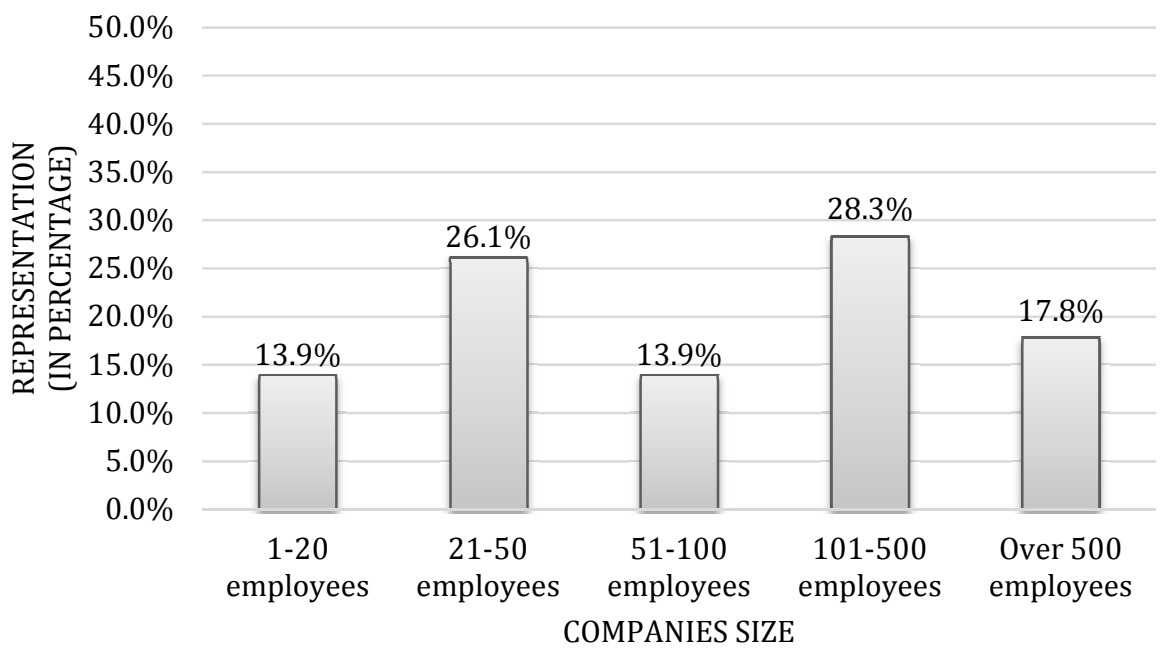

Figure 6: Respondent companies by size

Respondent individuals were overall well experienced, in terms of having both long careers and long-term employment in their current company.

The informants were also generally well educated; $81.6 \%$ of the respondents had a higher education of some sort. When asked to assess their self-perceived level of knowledge of cloud computing/SaaS and ERP systems, they overall felt more knowledgeable on the latter. 


\section{ERP usage and intention}

ERP adoption degree was relatively high in the sample as $75 \%$ of the total amount of respondents reported that they currently used one. The $11 \%$ that answered that they were likely to never use one were excluded from the sample, as explained in section 4.3. Consequently, $86 \%$ of the respondents in the final sample were currently using ERP systems. 56.1 \% had had ERP installations for more than 10 years. On-premises installations were quite predominant among the current systems, accounting for $67.7 \%$ of the installations. Organizations currently using cloud/SaaSbased ERP tended to be in the lower part of the spectrum in regard to size, with $14.8 \%$ having more than 100 employees. Adopters' industry domain did reflect the overall sample to a certain extent, with a notably higher degree of diffusion in the construction industry and a somewhat lower representation in the retail domain.

ERP systems were not only widely diffused among the respondents; they were also viewed as very mission critical. Correlation analyses were done in regard to company size (CS) and company installation type (CIT/CIT2), as well as among the answers themselves. Correlation analyses uncovered (a somewhat unsurprising) link between satisfaction with system and system age.

Table 2: Opinions regarding current installation

\begin{tabular}{|l|l|l|l|l|l|l|l|l|}
\hline Element & $\boldsymbol{\mu}$ & $\boldsymbol{\sigma}$ & $\begin{array}{l}\text { CORR: } \\
\text { CS }\end{array}$ & $\begin{array}{l}\text { CORR: } \\
\text { CIT }\end{array}$ & $\begin{array}{l}\text { CORR: } \\
\text { CIT2 }\end{array}$ & $\begin{array}{l}\text { CORR: } \\
\text { ORCI1 }\end{array}$ & $\begin{array}{l}\text { CORR: } \\
\text { ORCI2 }\end{array}$ & $\begin{array}{l}\text { CORR: } \\
\text { ORCI3 }\end{array}$ \\
\hline $\begin{array}{l}\text { ORCI1: } \\
\text { Satisfaction }\end{array}$ & 6.91 & 1.539 & -0.031 & 0.032 & 0.047 & - & -0.441 & 0.260 \\
\hline ORCI2: Outdated & 4.61 & 2.959 & 0.127 & 0.108 & 0.137 & - & - & -0.001 \\
\hline $\begin{array}{l}\text { ORCI3: Value } \\
\text { creation }\end{array}$ & 8.79 & 1.848 & 0.012 & 0.225 & 0.229 & - & - & - \\
\hline
\end{tabular}

\section{Perceived benefits}

Respondents found accessibility and scalability to be the most significant benefits, with a mean score of 7.71 and 7.04 respectively. In order to identify the spread of the response distribution, standard deviation $(\sigma)$ was calculated. Correlation analyses were performed based on CS, CIT/CIT2, perceived knowledge of ERP (PKERP) and cloud computing/SaaS (PKCS), intention (I), and attitude (ATT). The correlations presented in Table 3 reveal those adopters, both present and future, generally rated benefits slightly higher than their non-adopting counterparts. There is a strong overall correlation between high rating of benefits and a positive attitude toward cloud ERP. While lower TCO was not ranked particularly high score-wise, it has a notable correlation with the attitude construct. Other variables with notable attitude correlations are lower startup costs, scalability and strategic flexibility, and easier internal collaboration and data sharing. 
Table 3: Perceived benefits of cloud/SaaS-based ERP systems

\begin{tabular}{|c|c|c|c|c|c|c|c|c|c|}
\hline Element & $\mu$ & $\sigma$ & $\begin{array}{l}\text { CORR: } \\
\text { CS }\end{array}$ & $\begin{array}{l}\text { CORR: } \\
\text { CIT }\end{array}$ & $\begin{array}{l}\text { CORR: } \\
\text { CIT2 }\end{array}$ & $\begin{array}{l}\text { CORR: } \\
\text { PKERP }\end{array}$ & $\begin{array}{l}\text { CORR: } \\
\text { PKCS }\end{array}$ & $\begin{array}{l}\text { CORR: } \\
\text { I }\end{array}$ & $\begin{array}{l}\text { CORR: } \\
\text { ATT }\end{array}$ \\
\hline $\begin{array}{l}\text { PB1: Lower } \\
\text { TCO }\end{array}$ & 5.68 & 2.056 & 0.062 & -0.119 & -0.126 & 0.147 & 0.083 & -0.134 & 0.403 \\
\hline $\begin{array}{l}\text { PB2: Lower } \\
\text { demand for } \\
\text { internal } \\
\text { competency }\end{array}$ & 6.36 & 2.350 & -0.111 & -0.204 & -0.201 & -0.071 & 0.031 & -0.192 & 0.297 \\
\hline $\begin{array}{l}\text { PB3: Lower } \\
\text { maintenance } \\
\text { and upgrade } \\
\text { costs }\end{array}$ & 6.42 & 2.278 & 0.043 & -0.149 & -0.146 & 0.049 & 0.200 & -0.183 & 0.321 \\
\hline $\begin{array}{l}\text { PB4: Lower } \\
\text { startup costs }\end{array}$ & 6.32 & 2.191 & 0.009 & 0.036 & 0.046 & 0.096 & 0.261 & 0.035 & 0.141 \\
\hline $\begin{array}{l}\text { PB5: } \\
\text { Accessibility } \\
\text { anytime, } \\
\text { anywhere from } \\
\text { numerous } \\
\text { devices }\end{array}$ & 7.71 & 2.135 & -0.222 & -0.248 & -0.237 & 0.062 & -0.024 & -0.324 & 0.368 \\
\hline $\begin{array}{l}\text { PB6: Environ- } \\
\text { mentally } \\
\text { friendly }\end{array}$ & 5.47 & 2.214 & -0.009 & -0.166 & -0.167 & -0.095 & -0.041 & -0.119 & 0.334 \\
\hline $\begin{array}{l}\text { PB7: Scalability } \\
\text { and strategic } \\
\text { flexibility }\end{array}$ & 7.04 & 2.199 & -0.036 & -0.162 & -0.135 & 0.059 & 0.126 & -0.161 & 0.473 \\
\hline $\begin{array}{l}\text { PB8: Easier } \\
\text { internal } \\
\text { collaboration } \\
\text { and data } \\
\text { sharing }\end{array}$ & 6.04 & 2.508 & -0.232 & -0.317 & -0.328 & -0.017 & -0.056 & -0.284 & 0.412 \\
\hline
\end{tabular}

\section{Perceived disadvantages}

Respondents found vendor dependency to be the most negative aspect of cloud/SaaS ERP systems; with lack of customization options as the second largest issue (see Table 4). Reminiscent of the case of perceived benefits, there was an overall slight correlation between non-adopters and skeptics in regard to how they evaluated the disadvantages. Respondents with an on-premises installation or a limited degree of adoption intention appeared to view the different disadvantages more severely. Correlation analyses reveal that while PD7 has a low mean score, it has a somewhat significant correlation with ATT. PD2 and PD3 were also found to have notable correlation. 
Table 4: Perceived disadvantages of cloud/SaaS-based ERP systems

\begin{tabular}{|l|c|c|c|c|c|c|c|c|c|}
\hline Element & $\boldsymbol{\mu}$ & $\boldsymbol{\sigma}$ & $\begin{array}{c}\text { CORR: } \\
\text { CS }\end{array}$ & $\begin{array}{c}\text { CORR: } \\
\text { CIT }\end{array}$ & $\begin{array}{c}\text { CORR: } \\
\text { CIT2 }\end{array}$ & $\begin{array}{c}\text { CORR: } \\
\text { PKERP }\end{array}$ & $\begin{array}{c}\text { CORR: } \\
\text { PKCS }\end{array}$ & $\begin{array}{c}\text { CORR: } \\
\text { I }\end{array}$ & $\begin{array}{c}\text { CORR: } \\
\text { ATT }\end{array}$ \\
\hline $\begin{array}{l}\text { PD1: Lack of } \\
\text { standards }\end{array}$ & 5.64 & 2.003 & 0.110 & 0.299 & $\mathbf{0 . 3 3 6}$ & 0.083 & 0.162 & 0.128 & -0.158 \\
\hline $\begin{array}{l}\text { PD2: Data } \\
\text { ownership } \\
\text { and control }\end{array}$ & 6.53 & 2.588 & 0.019 & $\mathbf{0 . 2 8 8}$ & $\mathbf{0 . 3 2 6}$ & -0.028 & 0.069 & 0.236 & $\mathbf{- 0 . 3 3 4}$ \\
\hline $\begin{array}{l}\text { PD3: Lack of } \\
\text { customization }\end{array}$ & 6.84 & 2.355 & 0.236 & 0.393 & $\mathbf{0 . 4 4 9}$ & 0.176 & 0.227 & 0.296 & $\mathbf{- 0 . 4 5 2}$ \\
\hline $\begin{array}{l}\text { PD4: Service } \\
\text { downtime }\end{array}$ & 5.76 & 2.440 & -0.072 & 0.106 & 0.137 & 0.057 & 0.016 & 0.085 & -0.248 \\
\hline $\begin{array}{l}\text { PD5: } \\
\text { Bankrupt } \\
\text { service } \\
\text { provider }\end{array}$ & 6.54 & 2.214 & 0.038 & 0.160 & 0.183 & 0.060 & 0.076 & 0.071 & -0.196 \\
\hline $\begin{array}{l}\text { PD6: Vendor } \\
\text { dependency }\end{array}$ & 7.04 & 2.169 & -0.061 & -0.062 & -0.064 & 0.042 & 0.042 & -0.077 & -0.171 \\
\hline $\begin{array}{l}\text { PD7: Security } \\
\text { issues }\end{array}$ & 4.87 & 2.361 & 0.100 & 0.262 & $\mathbf{0 . 3 0 1}$ & 0.057 & 0.011 & 0.195 & $\mathbf{- 0 . 3 0 4}$ \\
\hline
\end{tabular}

\section{Attitude}

In section 3, it was explained that the attitude dimension of TPB is largely made up from the salient beliefs (in this case, the perceived benefits and disadvantages) held by the respondents. As seen above, the correlation between these beliefs and the ATT variable is generally quite high and goes a long way in validating these claims. Furthermore, ATT has a significant correlation with intention, which further consolidates the relationships described in TPB literature, as presented in Table 5.

Table 5: Attitude toward adoption

\begin{tabular}{|l|c|c|c|c|c|c|c|c|c|c|}
\hline Element & $\boldsymbol{\mu}$ & $\boldsymbol{\sigma}$ & $\begin{array}{c}\text { CORR: } \\
\text { CS }\end{array}$ & $\begin{array}{c}\text { CORR: } \\
\text { CIT }\end{array}$ & $\begin{array}{c}\text { CORR: } \\
\text { CIT2 }\end{array}$ & $\begin{array}{c}\text { CORR: } \\
\text { PKERP }\end{array}$ & $\begin{array}{c}\text { CORR: } \\
\text { PKCS }\end{array}$ & $\begin{array}{c}\text { CORR: } \\
\text { I }\end{array}$ & $\begin{array}{c}\text { CORR: } \\
\text { ORCI1 }\end{array}$ & $\begin{array}{c}\text { CORR: } \\
\text { ORCI2 }\end{array}$ \\
\hline $\begin{array}{l}\text { Attitude } \\
\text { toward } \\
\text { adoption }\end{array}$ & 5.62 & 2.238 & -0.241 & $\mathbf{- 0 . 5 0 2}$ & $\mathbf{- 0 . 5 0 8}$ & -0.052 & 0.147 & $\mathbf{- 0 . 5 2 4}$ & -0.027 & -0.158 \\
\hline
\end{tabular}

\section{Subjective norms and perceived behavioral control}

While not a central part of this study, respondents were nevertheless surveyed in terms of SN and PBC. Several correlation scores serve as indicators that the described relationships between TPB constructs $(\mathrm{SN} \rightarrow \mathrm{I}, \mathrm{PBC} \rightarrow \mathrm{I})$ are valid also here. The results are shown in Table 6 below. 
Table 6: Perceived subjective norms and perceived behavioral control

\begin{tabular}{|l|l|c|c|c|c|c|}
\hline Element & M & $\sigma$ & $\begin{array}{c}\text { CORR: } \\
\text { CS }\end{array}$ & $\begin{array}{c}\text { CORR: } \\
\text { CIT }\end{array}$ & $\begin{array}{c}\text { CORR: } \\
\text { CIT2 }\end{array}$ & $\begin{array}{c}\text { CORR: } \\
\text { I }\end{array}$ \\
\hline $\begin{array}{l}\text { SN1: Decisions are highly } \\
\text { affected by significant others' } \\
\text { opinions }\end{array}$ & 6.80 & 2.158 & -0.046 & -0.207 & -0.195 & -0.288 \\
\hline $\begin{array}{l}\text { SN2: Expert opinion on cloud } \\
\text { technology is heeded }\end{array}$ & 5.59 & 2.147 & -0.047 & -0.310 & -0.262 & -0.386 \\
\hline $\begin{array}{l}\text { SN3: Significant others are in } \\
\text { favor of adoption }\end{array}$ & 4.98 & 2.512 & -0.223 & -0.500 & -0.522 & -0.534 \\
\hline $\begin{array}{l}\text { SN4: Significant others are } \\
\text { positive toward cloud } \\
\text { technology }\end{array}$ & 5.79 & 2.390 & -0.092 & -0.315 & -0.369 & -0.363 \\
\hline $\begin{array}{l}\text { PBC1: The adoption is to a } \\
\text { large extent the respondent's } \\
\text { decision }\end{array}$ & 5.77 & 2.736 & -0.131 & -0.111 & -0.136 & -0.213 \\
\hline $\begin{array}{l}\text { PBC2: The company has the } \\
\text { necessary resources for } \\
\text { adoption }\end{array}$ & 5.99 & 2.602 & 0.052 & -0.273 & -0.283 & -0.321 \\
\hline
\end{tabular}

\section{Regression analysis}

To uncover which salient beliefs hold the highest predictive impact on attitude toward cloud- and SaaS-based ERP systems, a regression analysis was applied. Cartmanand Salazar (2011) recommends limiting regression analyses to variables with a certain correlation. In this case, the benefits and disadvantages with a sufficiently strong correlation with ATT were PB1 (0.40), PB3 (0.32), PB5 (0.36), PB6 (0.33), PB7 (0.47), PB8 (0.41), PD2 $(-0.33)$, PD3 $(-0.45)$, and PD7 $(-0.30)$. These were subjected to a regression analysis with ATT as the dependent variable (Y). The analyses were conducted on three different segments of the sample:(1) the total sample, (2) current adopters of cloud/SaaS ERP, and (3) onpremises ERP adopters.

Table 7: Regression analysis - Overall

\begin{tabular}{|c|c|c|c|c|c|c|c|c|}
\hline $\begin{array}{c}\text { Dep. variables: Total } \\
\text { Sample }\end{array}$ & $\begin{array}{c}\text { Observation } \\
\mathbf{s}\end{array}$ & $\mathbf{f}$ & $\mathbf{R}$ & $\mathbf{R} \wedge 2$ & $\mathbf{S E}$ & $\mathbf{t}$ & Coeff. & Sig.(P) \\
\hline PB1 & 179 & 878.17 & .40 & .16 & 2.04 & 5.8610 & 0.44 & $0.000^{* * *}$ \\
\hline PB3 & 179 & 878.17 & .32 & .10 & 2.11 & 4.5224 & 0.31 & $0.000^{* * *}$ \\
\hline PB5 & 179 & 878.17 & .37 & .14 & 2.07 & 5.2702 & 0.38 & $0.000^{* * *}$ \\
\hline PB6 & 179 & 878.17 & .33 & .11 & 2.10 & 4.7240 & 0.34 & $0.000^{* * *}$ \\
\hline
\end{tabular}




\begin{tabular}{|c|c|c|c|c|c|c|c|c|}
\hline PB7 & 179 & 878.17 & .47 & .22 & 1.96 & 7.1513 & 0.48 & $0.000^{* * *}$ \\
\hline PB8 & 179 & 878.17 & .41 & .17 & 2.03 & 6.0245 & 0.37 & $0.000^{* * *}$ \\
\hline PD2 & 178 & 876.25 & .33 & .11 & 2.10 & -4.7109 & -0.29 & $0.000^{* * *}$ \\
\hline PD3 & 178 & 878.02 & .45 & .20 & 1.99 & -6.7260 & -0.43 & $0.000^{* * *}$ \\
\hline PD7 & 177 & 871.26 & .30 & .09 & 2.12 & -4.2481 & -0.29 & $0.000^{* * *}$ \\
\hline
\end{tabular}

Table 8: Regression analysis - Adopters

\begin{tabular}{|l|c|c|c|c|c|c|c|c|}
\hline $\begin{array}{l}\text { Dep. variables: Total } \\
\text { Sample }\end{array}$ & $\begin{array}{c}\text { Observation } \\
\mathbf{s}\end{array}$ & $\mathbf{f}$ & $\mathbf{R}$ & $\mathbf{R} \wedge \mathbf{2}$ & $\mathbf{S E}$ & $\mathbf{t}$ & Coeff. & Sig. (P) \\
\hline PB1 & 26 & 66.15 & .60 & .36 & 1.33 & 3.6706 & 0.43 & $0.001^{* *}$ \\
\hline PB3 & 26 & 66.15 & .45 & .20 & 1.48 & 2.4572 & 0.29 & $0.022^{*}$ \\
\hline PB5 & 26 & 66.15 & .48 & .23 & 1.46 & 2.6588 & 0.48 & $0.014^{*}$ \\
\hline PB6 & 26 & 66.15 & .44 & .20 & 1.49 & 2.4317 & 0.32 & $0.023^{*}$ \\
\hline PB7 & 26 & 66.15 & .58 & .33 & 1.36 & 3.4538 & 0.45 & $0.002^{* *}$ \\
\hline PB8 & 26 & 66.15 & .35 & .12 & 1.55 & 1.8502 & 0.27 & 0.077 \\
\hline PD2 & 25 & 65.76 & .31 & .10 & 1.61 & -1.5674 & -0.19 & 0.131 \\
\hline PD3 & 26 & 66.15 & .23 & .005 & 1.61 & -1.1737 & -0.16 & 0.252 \\
\hline PD7 & 26 & 66.15 & .14 & .002 & 1.64 & -0.7107 & -0.11 & 0.484 \\
\hline
\end{tabular}

Table 9: Regression analysis - Non-adopters

\begin{tabular}{|l|c|c|c|c|c|c|c|c|}
\hline $\begin{array}{l}\text { Dep. variables: Total } \\
\text { Sample }\end{array}$ & $\begin{array}{c}\text { Observation } \\
\mathbf{S}\end{array}$ & $\mathbf{f}$ & $\mathbf{R}$ & $\mathbf{R} \mathbf{R}^{\wedge}$ & $\mathbf{S E}$ & $\mathbf{t}$ & Coeff. & Sig. (P) \\
\hline PB1 & 105 & 446.06 & .33 & .11 & 1.96 & 3.6066 & 0.34 & $0.000^{* * *}$ \\
\hline PB3 & 105 & 446.06 & .19 & .04 & 2.04 & 1.9371 & 0.17 & 0.055 \\
\hline PB5 & 105 & 446.06 & .33 & .11 & 1.96 & 3.6059 & 0.30 & $0.000^{* * *}$ \\
\hline PB6 & 105 & 446.06 & .24 & .06 & 2.02 & 2.5199 & 0.23 & $0.013^{*}$ \\
\hline PB7 & 105 & 446.06 & .46 & .21 & 1.85 & 5.2812 & 0.40 & $0.000^{* * *}$ \\
\hline PB8 & 106 & 446.06 & .19 & .04 & 2.04 & 1.9699 & 0.16 & 0.052 \\
\hline PD2 & 105 & 446.06 & .17 & .03 & 2.05 & -1.7589 & -0.15 & 0.082 \\
\hline PD3 & 104 & 444.46 & .43 & .19 & 1.88 & -4.8364 & -0.43 & $0.000^{* * *}$ \\
\hline PD7 & 104 & 442.99 & .19 & .04 & 2.05 & -1.9617 & -0.17 & 0.053 \\
\hline
\end{tabular}


The P-values indicate a good model fit on all the dependent variables when measuring the total sample. The significance values differ more when reviewing adopters and non-adopters. For the total sample as well as for nonadopters, the dependent variables with the highest predictive values are PB1, PB7, PB8, and PD3. For adopters, PB1 and PB7 are highest, along with PB5, which has a lower model fit.

Based on our regression analysis and the findings presented above, the following section presents the supported and unsupported hypotheses:

H1a: Lower TCO is the most significant benefit. Not supported

H1b: TCO is a significant predictor of attitude. Supported

H2a: Security concerns are the most significant disadvantage. Not supported H2b: Security concerns are the most significant predictor of attitude. Not supported

H3a: Accessibility is perceived as a significant benefit. Supported

H3b: Accessibility is a significant predictor of attitude. Supported

\section{Discussion}

The regression analysis reveals that scalability and easier collaboration are both benefits with relatively significant predictive qualities toward attitude, while vendor dependency is a negative trait with a similar impact. The high ranking of scalability/strategic flexibility, as well as the concerns regarding vendor dependency and limited tailoring capabilities, goes a long way in confirming the tendencies found in the reviewed literature. One exceptional finding is related to the TCO element. Contrary to the preliminary assumption, our participants did not believe lower TCO to be a particularly strong benefit of cloud ERP. No segmented group of respondents viewed it as such; in fact, it was predominantly found in the lower category of the range, in both the overall sample and the segmented subsamples. As found in the literature, subscription fees for both modules and users may turn out to be quite costly in the long run, and cost efficiency is overall highly context and size sensitive (Arnesen, 2013). Survey respondents might be aware of this and thus evaluate TCO lower as a result. TCO does, however, appear to have a relatively strong predictive value in terms of attitude across all segments. The low weighting of TCO might be partly explained by the presence of other cost-oriented benefits, such as those related to upgrade, maintenance, and implementations affect the rankings. These are central elements of the total lowered TCO, and it is possible that a fusion of all cost-related benefits into one variable would receive a different response. Another unexpected outcome was in regard to data security. The issue of data security was by no means a key concern of the respondents, as both the total sample and all segmented subsamples rated it as the least significant disadvantage (except respondents from the IT and technology industry, who weighted it second last). Nor did it hold any particular predictive power for attitude. This contradicts the general tendencies found in cloud/SaaS literature. It does, however, fit Juell-Skielse and Enquist's (2012) claim that security has become less of an issue lately. Moreover, it is possible that the low concerns in regard to security are of a sociocultural character. The study was conducted in Norway, a country whose population generally has a rather lax attitude toward data security concerns (Datatilsynet, 2014). A somewhat more generalizable - and arguably probable explanation is the rising degree of pervasiveness of cloud technology and services. People's daily interactions with everything from online social networks to banking services might reduce their concerns toward the data security aspect of web-based applications.

Although vendors may rejoice over the reported lack of concerning regard to data security, it should not inspire a relaxing of efforts in this field. It is likely that these perceptions are quite volatile and may be highly affected by certain events and media coverage of these. The Norwegian Data 
Protection Authority found that the case of Edward Snowden significantly increased the data security concerns of Norwegian citizens (Datatilsynet, 2014). It seems uncontroversial to assume that a majorscale corporate data security "crisis" could have a similar effect on IT professionals' perceptions.

Accessibility was assumed to be a significant benefit and a significant predictor of attitude. The first turned out to be somewhat of an understatement, as accessibility was - with a significant lead perceived to be the most compelling benefit. While not entirely insignificant, it was not, however, among the strongest dependent variables with the highest predictive potential. The perceived importance of accessibility may be somewhat intensified by certain current technology trends. The emergence of portable computing devices such as laptops, smartphones, and tablets has had a tremendous impact on both society and corporate life (Pitt, Berthon, \& Robson, 2011). In 2013, $73 \%$ and $61 \%$ of the Norwegian population had access to smartphones and tablets, respectively (Sentralbyrå, 2014). Businesses and organizations are not unaffected by this phenomenon; the advent of concepts such as BYOD (bring your own device) and the staggering growth of the use of gadgets in enterprise contexts serves as proof (Harris, Ives, \&Junglas, 2012). In such a mobilitydriven work environment, it seems uncontroversial to think that instant and location-independent access to the ERP system is a significant boon. This is reflected in an extensive ERP survey conducted by Christensen (2011), who discovered that $63.5 \%$ of respondents either somewhat or entirely agreed that a modern ERP system should be able to offer services on smartphones and tablets.

Despite the hardships associated with onpremises ERP implementations, respondents did not view the less expensive and exhaustive process of cloud and SaaS ERP implementation to be a particularly significant benefit. This could indicate that the same challenges of intraorganizational adaption to the new system (Elragal \& Haddara, 2012) very much apply to cloud/SaaS ERP as well, and that they are weighed more heavily than monetary benefits. It is also interesting to note that this benefit is ranked lower by current cloud/SaaS ERP adopters than by on-premises users and future adopters. We might be witnessing a dissonance between expectations and reality on this particular aspect.

\section{Conclusions and Future Research Avenues}

Cloud applications are acquiring increasing interest from academia and practice alike. Vendors providing cloud ERP guarantee their clients' rapid adoption, high benefits realization, and substantial cost reductions. While cloud ERP systems are currently enjoying a growing diffusion, however, they have rarely been subject to extensive empirical research. The findings in this study expand the body of knowledge on IT professionals' beliefs and attitudes toward cloud ERP systems. These findings might prove to be highly valuable for cloud ERP vendors, both present and future, as they give insights into what their target audience perceives as their biggest strengths and concerns. Their promise of accessibility and their scalable nature were found to be the systems' most appealing characteristics. At the same time, there were concerns about their inherent tendency to make clients more dependent on the system vendors, as well as their limited customization options compared to on-premises ERP solutions. In opposition to its frequent expression in existing literature, the issue of data security was not perceived as a major concern at all. This might be because of an increasing trust in vendors' mature security measures, the widespread usage of mobile systems, or Norwegian culture. In addition, SMEs may believe that they cannot afford or provide high security measures themselves, owing to scarcity of resources or skills. The decrease of security concerns needs more research to be explained. It is possible that the results from this study, especially the seemingly increased attraction of system accessibility and the decline of security concerns, can be explained by certain 
current technological trends. Other versions of this survey could be conducted in different countries and contexts in order to uncover whether these findings resonate in a broader social context. In addition, the findings might be transferable to other enterprise systems, such as customer relationship systems. If the study results are proven to be representative of the zeitgeist among the world's IT professionals, then cloud ERP may have overcome a significant barrier for adoption, which is the security concern. On the other hand, cloud ERP vendors should also focus on tackling other concerns, including dependability and interoperability.

\section{Notes:}

${ }^{1}$ http://download.1105media.com/GIG/Cu stom/2011PDFS/CloudComputing/CloudC omputingLM.pdf

${ }^{2}$ http://no.wikipedia.org/wiki/Kategori:No rske_selskaper

${ }^{3}$ CIT2 excludes hybrid/hosted solutions.

\section{References}

1. Ajzen, I. (1985). From intentions to actions: A theory of planned behavior: Springer.

2. Ajzen, I. (1991). The theory of planned behavior. Organizational behavior and human decision processes, 50(2), 179211.

3. Ajzen, I. (2002). Constructing a TPB questionnaire: Conceptual and methodological considerations.

4. Ajzen, I., \& Fishbein, M. (1980). Understanding attitudes and predicting social. Behaviour. Englewood Cliffs, NJ: Prentice-Hall.

5. Armbrust, M., Fox, A., Griffith, R., Joseph, A., Katz, R., Konwinski, A., . . . Rabkin, A. (2010). A view of cloud computing. Communication of the ACM, 53(4), 50-58.
6. Armbrust, M., Fox, A., Griffith, R., Joseph, A., Katz, R., Konwinski, A., . . . Stoica, I. (2010). Above the Clouds: A View of Cloud Computing: Technical report.

7. Arnesen, S. (2013). Is cloud ERP solution right for you. Strategic Finance, 95(2), 45-50.

8. Beheshti, H. (2006). What managers should know about ERP/ERP II. Management Research News, 29(4), 184-193.

9. Benlian, A., \& Hess, T. (2011). Opportunities and risks of software-asa-service: Findings from a survey of IT executives. Decision Support Systems, 52(1), 232-246.

10. Benlian, A., Hess, T., \& Buxmann, P. (2009). Drivers of SaaS-adoption-an empirical study of different application types. Business \& Information Systems Engineering, 1(5), 357-369.

11. Carr, N. G. (2005). The End of Corporate Computing. Sloan Management Review, 67-73.

12. Cartman, C., \& Salazar, A. (2011). The influence of organisational size, internal IT capabilities, and competitive and vendor pressures on ERP adoption in SMEs. International Journal of Enterprise Information Systems (IJEIS), 7(3), 68-92.

13. Castellina, N. (2011). SaaS and Cloud ERP Trends, Observations, and Performance 2011. Analyst Inside.

14. Castellina, N. (2012). SaaS and Cloud ERP Observations: Is Cloud ERP Right For You? : Aberdeen Group.

15. Castellina, N. (2013). SaaS and Cloud ERP Observations: Enabling Collaboration in the Midmarket.

16. Chang, M. K. (1998). Predicting unethical behavior: a comparison of the theory of reasoned action and the theory of planned behavior. Journal of business ethics, 17(16), 1825-1834. 
17. Chau, P. Y., \& Hu, P. J. H. (2001). Information technology acceptance by individual professionals: A model comparison approach*. Decision Sciences, 32(4), 699-719.

18. Christensen, H. (2011). ERPundersøkelsen 2011: Common Norge.

19. CIA. (2014). Central Intelligence Agency - The World Factbook.

20. Co, H. (2013). Forretningssystemer i Norge 2013. Oslo: HerbertNathan \& Co.

21. Columbus, L. (2012). SaaS Adoption Accelerates, Goes Global in the Enterprise: Preluat de pe http://softwarestrategiesblog. com/category/competitive-analysis.

22. Columbus, L. (2014). Why Cloud ERP Adoption Is Faster Than Gartner Predicts.Retrieved 12-Aug, 2014, from http://www.forbes.com/sites/louiscol umbus/2014/02/07/why-cloud-erpadoption-is-faster-than-gartnerpredicts/

23. Datatilsynet. (2014). Personvern tilstand og trender 2014.

24. Davis, F. D. (1985). A technology acceptance model for empirically testing new end-user information systems: Theory and results. Massachusetts Institute of Technology.

25. Deltour, F. (2012). ERP Project in SMEs: a Matter of Risks, a Matter of Competencies. A Quantitative Analysis. Paper presented at the ECIS 2012, Barcelona.

26. Elragal, A., \& Haddara, M. (2010). The Use of Experts Panels in ERP Cost Estimation Research. Communications in Computer and Information Science, 110, 97-108.

27. Elragal, A., \& Haddara, M. (2012). The Future of ERP Systems: look backward before moving forward. Procedia Technology, 5(0), 21-30. doi: 10.1016/j.protcy.2012.09.003
28. Elragal, A., \& Haddara, M. (2013). The Impact of ERP Partnership Formation Regulations on the Failure of ERP Implementations. Procedia Technology, 9(2013), 525-537.

29. Feuerlicht, G., Burkon, L., \& Sebesta, M. (2011). Cloud Computing Adoption: What are the Issues. Systémová integrace, 187-192.

30. Finney, S., \& Corbett, M. (2007). ERP implementation: a compilation and analysis of critical success factors. Business Process Management Journal, 13(3), 329-347.

31. Francis, J. J., Eccles, M. P., Johnston, M., Walker, A., Grimshaw, J., Foy, R., . . . Bonetti, D. (2004). Constructing questionnaires based on the theory of planned behaviour. A manual for health services researchers, 2010, 2-12.

32. Ghaffari, K., Delgosha, M. S., \& Abdolvand, N. (2014). Towards Cloud Computing: A SWOT Analysis on its Adoption in SMEs. arXiv preprint arXiv:1405.1932.

33. Gill, R. (2011). Why cloud computing matters to finance. Strategic Finance, 92(7), 43-47.

34. Grenness, T. (2003). Scandinavian managers on Scandinavian management. International Journal of Value-Based Management, 16(1), 9-21.

35. Haddara, M. (2011). ERP Adoption Cost Factors in SMEs. Paper presented at the European, Mediterranean and Middle Eastern Conference on Information Systems (EMCIS), Athens, Greece.

36. Haddara, M. (2012). Exploring ERP Adoption Cost Factors. Journal of Computer Technology \& Applications (JCTA), 3(3), 250-261.

37. Haddara, M. (2014). ERP Selection: The SMART Way. Procedia Technology, 16, 394-403.

38. Haddara, M., \& Elragal, A. (2013). ERP adoption cost factors identification and 
classification: a study in SMEs. International Journal of Information Systems and Project Management, 1(2), 5-22.

39. Haddara, M., \& Zach, O. (2012). ERP Systems in SMEs: An Extended Literature Review. International Journal of Information Science, 2(6), 106-116.

40. Harris, J., Ives, B., \& Junglas, I. (2012). IT consumerization: when gadgets turn into enterprise IT tools. MIS Quarterly Executive, 11(3), 99-112.

41. Harrison, D. A., Mykytyn Jr, P. P., \& Riemenschneider, C. K. (1997). Executive decisions about adoption of information technology in small business: theory and empirical tests. Information systems research, 8(2), 171-195.

42. Hofmann, P., \& Woods, D. (2010). Cloud computing: the limits of public clouds for business applications. Internet Computing, IEEE, 14(6), 90-93.

43. Hofstede, G. (1983). The cultural relativity of organizational practices and theories. Journal of international business studies, 75-89.

44. Hustad, E., \& Olsen, D. H. (2014). ERP Implementation in an SME: a Failure Case Information Systems for Small and Medium-sized Enterprises (pp. 213228): Springer.

45. Iyer, B., \& Henderson, J. C. (2010). PREPARING FOR THE FUTURE: UNDERSTANDING THE SEVEN CAPABILITIES CLOUD COMPUTING. MIS Quarterly Executive, 9(2).

46. Jacobson, S., Shepherd, J., D'Aquila, M., \& Carter, K. (2007). The ERP market sizing report, 2006-2011. AMR Research, 29.

47. Juell-Skielse, G., \& Enquist, H. (2012). Implications of ERP as Service $R e$ conceptualizing Enterprise Information Systems (pp. 129-151): Springer.
48. Kanaracus, C. (2014). Gartner: Today's On-Premises ERP Systems Will Soon Get the 'legacy' Label.Retrieved 12Aug, 2014, from http://www.cio.com/article/747329/ Gartner_Today_39_s_On_premises_ERP _Systems_Will_Soon_Get_the_39_legacy _39_Label

49. Koehler, P., Anandasivam, A., \& Dan, M. (2010). Cloud services from a consumer perspective.

50. Lenart, A. (2011). ERP in the CloudBenefits and Challenges Research in systems analysis and design: Models and methods (pp. 39-50): Springer.

51. Lewandowski, J., Salako, A. O., \& GarciaPerez, A. (2013). SaaS Enterprise Resource Planning Systems: Challenges of Their Adoption in SMEs. Paper presented at the e-Business Engineering (ICEBE), 2013 IEEE 10th International Conference on.

52. Linthicum, D. S. (2009). Cloud computing and SOA convergence in your enterprise: a step-by-step guide: Pearson Education.

53. Madden, T. J., Ellen, P. S., \& Ajzen, I. (1992). A comparison of the theory of planned behavior and the theory of reasoned action. Personality and social psychology Bulletin, 18(1), 3-9.

54. Marston, S., Li, Z., Bandyopadhyay, S., Zhang, J., \& Ghalsasi, A. (2011). Cloud computing-The business perspective. Decision Support Systems, 51(1), 176189.

55. Mathieson, K. (1991). Predicting user intentions: comparing the technology acceptance model with the theory of planned behavior. Information systems research, 2(3), 173-191.

56. Mell, P., \& Grance, T. (2011). The NIST definition of cloud computing.

57. Møller, C. (2005). ERP II: a conceptual framework for next-generation enterprise systems? Journal of 
Enterprise Information Management, 18(4), 483 - 497.

58. Montano, D. E., \& Kasprzyk, D. (2008). Theory of reasoned action, theory of planned behavior, and the integrated behavioral model. Health behavior and health education: Theory, research, and practice, 4, 67-95.

59. NorSIS. (2010). Fire av ti bryr seg ikke.Retrieved 12-Aug, 2014, from https://admin.norsis.no/nyheter/201 0-09-09-Fire-av-ti-bryr-seg-ikke.html

60. O'keefe, D. J. (2002). Persuasion: Theory and research (Vol. 2): Sage.

61. Oates, B. J. (2005). Researching information systems and computing: Sage.

62. Panorama Consulting Solutions, (2014). ERP report 2014.

63. Pitt, L., Berthon, P., \& Robson, K. (2011). Deciding When to Use Tablets for Business Applications. MIS Quarterly Executive, 10(3).

64. Rogers, E. M. (2010). Diffusion of innovations: Simon and Schuster.

65. Salim, S. A. (2013). Cloud ERP Adoption-A Process View Approach.

66. Salleh, S., Teoh, S., Chan, C., Pan, S. L., \& Cao, T. H. (2012). Cloud Enterprise Systems A Review of Literature and its Adoption. Paper presented at the
Proceedings of the Pacific Asia Conference on Information Systems, PACIS.

67. Sentralbyrå, S. (2014). Virksomheter, 1. januar 2014.Retrieved 12-Aug, 2014, from

http://www.ssb.no/virksomheter-

foretak-og-

regnskap/statistikker/bedrifter

68. Shimba, F. (2010). Cloud computing: Strategies for cloud computing adoption. Saarbrücken: Lambert Academic Publishers.

69. Torbacki, W. (2008). SaaS-direction of technology development in ERP/MRP systems. Archives of Materials Science, $58,58$.

70. Wu, W.-W. (2011). Developing an explorative model for SaaS adoption. Expert systems with applications, 38(12), 15057-15064.

71. Xin, M., \& Levina, N. (2008). Softwareas-a service model: Elaborating clientside adoption factors.

72. Zhang, Q., Cheng, L., \& Boutaba, R. (2010). Cloud computing: state-of-theart and research challenges. Journal of internet services and applications, 1(1), 7-18.

73. Zhao, L., Sakr, S., Liu, A., \& Bouguettaya, A. (2014). Cloud Data Management: Springer. 